\title{
Influence of different installation positions of keel on the resistance performance of pilot boat
}

\author{
Yu Xingpeng, Guan Yifeng
}

\begin{abstract}
Considering that the pilot vessel needs to be equipped with keel keel, pressure wave board and other attachments due to the ship's characteristics and improved navigation performance, these attachments have a greater impact on the total resistance of the hull. Since the bilge keel is widely used as the anti-rolling device for various types of seagoing vessels, its installation position has certain influence on the ship's resistance and anti-rolling performance. In this paper, the ship's resistance test and numerical calculation method are used to compare the resistance performance of the keel with different positions on a $16 \mathrm{~m}$ pilot ship. That is, when the resistance is relatively small, the proper installation position of the keel is determined to achieve the best. Sailing effect. And verify the reliability of the calculation method and the specific impact of the keel on the total resistance performance.
\end{abstract}

Index Terms-Pilot Boat, Keel, Ship.

\section{INTRODUCTION}

Pilotage is an important guarantee for port security and an important component of the smooth entry and exit of ships. As a important tool for pilotage, the pilot boat's resistance performance is directly related to its own piloting capacity and the crew's personal safety. Therefore, the resistance performance of the pilot vessel should be highly valued. At present, the resistance calculation method mainly includes two methods: model test and numerical calculation. However, although numerical calculations have developed rapidly in recent years, the theoretical calculation results and whether the design of new ship types can achieve the expected results require ship model tests to verify. Therefore, ship model test is still the most common and effective method for ship performance research ${ }^{[1]}$.

In order to improve the ship's anti-wave performance when sailing in heavy winds and waves, and reduce the six-degree-of-freedom movement of the hull, especially the roll motion, various active or passive anti-rolling measures are usually adopted in the design, including the setting of the keel and the anti-rolling Fins, anti-rolling water tanks, rudder rudders, and combined anti-rolling and rudder fins of fin stabilizers and anti-rolling tanks ${ }^{[2]}$. Among them, the keel keel is widely used, and the keel keel is fixedly installed in the hull of the hull. The keel is mainly used to reduce the rolling damping by changing the pressure difference between the front and back of the keel plate and changing the surface pressure distribution of the hull. The anti-rolling effect is not affected by the speed ${ }^{[3]}$. At present, it is not possible to design the shape and size of the bilge keel with a complete theoretical

Yu Xingpeng, School of Naval Architecture \& Ocean Engineering, Jiangsu University of Science and Technology, Zhenjiang 212003, China

Guan Yifeng, School of Naval Architecture \& Ocean Engineering, Jiangsu University of Science and Technology, Zhenjiang 212003, China calculation method, mainly relying on the ship model test or empirical formula as the basis.In 2012, Ganshui from Shanghai Waigaoqiao Shipbuilding Co., Ltd. carried out structural design and installation research on the conventional bulk carrier and oil tanker, and gave the typical structure, component size and design requirements of the bilge keel The material requirements of the keel and the details of the structure and the installation and positioning requirements, especially the requirements of the end are discussed in detail [4]; Fu Jiangyan, Chen Yu and others of the China Ship Research and Design Center in 2015 added The influence of keel on the hydrostatic resistance of a thousand-ton deep V-type ship was studied in depth, and the numerical simulation calculation was carried out to compare the hydrostatic resistance test. The test results show that the hydrostatic resistance increase after the installation of the keel of the thousand-ton deep V ship type Not more than 5\% ${ }^{[5]}$; Fang Advanced et al. conducted a resistance performance analysis of a medium-high speed fishery vessel with a keel keel attached, and verified the reliability of the calculation method and various pairs of pairs by comparing the calculation results with the ship model test results. The specific impact of total resistance performance ${ }^{[6]}$.

In this paper, we focus on the relative position of the keel keel arrangement, the impact on the rapidity of the pilot vessel, that is, the drawing data and test requirements of a $16 \mathrm{~m}$ pilot vessel, and complete the ship model resistance test under various conditions. The total resistance measured by the bare hull ship model test is compared with the calculated results to verify the reliability of the forecasting method. By analyzing the Reynolds number of the ship and its Froude number, according to the ship's line type and the performance of the ship, the ship model under the corresponding scale ratio was made, and the ship model test was carried out in the laboratory.

In this paper, we focus on the relative position of the keel keel arrangement, the impact on the rapidity of the pilot vessel, that is, the drawing data and test requirements of a $16 \mathrm{~m}$ pilot vessel, and complete the ship model resistance test under various conditions. The total resistance measured by the bare hull ship model test is compared with the calculated results to verify the reliability of the forecasting method. By analyzing the Reynolds number of the ship and its Froude number, according to the ship's line type and the performance of the ship, the ship model under the corresponding scale ratio was made, and the ship model test was carried out in the laboratory. The hull simulation results of the keel keel were compared with the bare hull simulation results to study the specific effects of the bilge keel on the total resistance performance. Through the mesh refinement and the addition of the boundary layer, the influence of the keel keel on the resistance is captured, and it is used as a means for the analysis and optimization of such sheet attachments in the early stage. 


\section{BASIC METHOD OF RESISTANCE CONVERSION}

\section{A. The basic idea of the ship model resistance conversion} method

The purpose of the ship model resistance test is mainly to convert the ship model resistance obtained from the test to the total hydrostatic resistance or effective power of the actual ship. There are two main conversion methods: one is Fu Zide's algorithm (two-times algorithm), and the other is three-times algorithm $(1+\mathrm{k})$, which is due to the Fu-German method. The combination of two different kinds of forces is not only theoretically inappropriate, but also practical, especially for the mast ship, the friction coefficient is negative. Therefore, this paper mainly uses the second method for ship model. Resistance conversion ${ }^{[7]}$.

In the treatment of several resistance components by the three-factor conversion method, the cohesive resistance and the frictional resistance are combined into the viscous resistance and related to the Reynolds number; the wave-making resistance is related to the $\mathrm{Fu}$-De number; according to the ship model test results, the cohesive resistance is considered. The ratio of the coefficient to the frictional resistance coefficient is a constant $\mathrm{k}$, then :

$$
\mathrm{k}=C_{\mathrm{pv}} / C_{\mathrm{f}} \text { or } 1+k=C_{\mathrm{v}} / C_{\mathrm{f}}
$$

Where $\mathrm{k}$ is called the shape factor and $(1+\mathrm{k})$ is the shape factor, which is only related to the shape of the hull.

1.1 Resistance conversion relationship of three-dimensional conversion method

Ship model total drag coefficient:

$$
\begin{aligned}
C_{T \mathrm{~m}} & =\frac{R_{T \mathrm{~m}}}{0.5 \rho_{\mathrm{m}} S_{\mathrm{m}} V_{\mathrm{m}}{ }^{2}} \\
C_{\mathrm{wm}} & =C_{T m}-(1+k) C_{F \mathrm{~m}} \\
C_{F \mathrm{~m}} & =\frac{0.075}{\left(\lg R_{\mathrm{em}}-2\right)^{2}} \\
R_{e m} & =\frac{V_{M} L_{W L}}{v_{m}} \\
\Delta C_{F} & =\left[105\left(\frac{K_{S}}{L_{W L}}\right)^{1 / 3}-0.64\right] \times 10^{-3}
\end{aligned}
$$

Total ship's total drag Coefficient:

$$
C_{T S \mathrm{~b}}=\frac{S+S_{\mathrm{bk}}}{S}\left[(1+K) C_{F S}+\Delta C_{F}\right]+C_{w m}+C_{A A}
$$

Total resistance of the actual ship:

$$
R_{T S}=0.5 C_{T S} \rho_{S} S_{S} V_{S}^{2}
$$

Effective power:

$$
P_{E}=\frac{R_{T S} V_{S}}{1000}
$$

In the formula: $C_{T m}$ :Total resistance coefficient of the ship model; $R_{T \mathrm{~m}}$ :Total resistance of the ship model; $\rho_{\mathrm{m}}:$ Pool water density; $S_{\mathrm{m}}$ :Wet surface area of ship model; $V_{\mathrm{m}}:$ Ship model speed $C_{R}$ :Residual drag coefficient; $C_{F \mathrm{~m}}$ :Ship model friction coefficient; $R_{e m}$ :Ship model Reynolds number; $L_{W L}$ :The ship model water line is long; $v_{\mathrm{m}}$ :The coefficient of motion viscosity of the pool water; $K_{S}$ :The surface roughness of the hull can generally be taken as $150 \times 10^{-6} \mathrm{~m} ; C_{A A}=0.001 \frac{A_{T}}{S_{S}} A_{T}:$ The theme above the ship's waterline and the projected area of the superstructure on the middle cross section; $S_{S}$ :Solid ship wet surface area; $\rho_{S}$ :Actual seawater density here takes $15^{\circ} \mathrm{C}$ seawater density $S_{S}$ :Solid ship wet surface area $V_{S}$ :Actual ship speed.

\section{POOL MODEL TEST STUDY}

\section{A. Introduction of main parameters and model making}

The ship model of the $16 \mathrm{~m}$ pilot ship is wood, the surface is painted and polished, and it is smooth and smooth. The ship model is equipped with a keel, and a squirt wire $(\varphi=1 \mathrm{~mm})$ is installed at the $\mathrm{L} / 20$ from the bow. After inspection and acceptance, the model processing accuracy is in line with the requirements of the machining accuracy of the model in the guidance technical documents of China National Shipbuilding Corporation CB/Z239-89. The parameters of the ship model and the actual ship ${ }^{[8]}$ are shown in Table 1.

Table 1 Ship's main scale and ship model parameters

\begin{tabular}{lllll}
\hline \multicolumn{1}{c}{$\begin{array}{c}\text { Main scale and its } \\
\text { parameters }\end{array}$} & symbol & unit & model & Real ship \\
\hline Total length & Loa & $\mathrm{m}$ & 1.9 & 15.6 \\
Water line length & Lwl & $\mathrm{m}$ & 1.875 & 15 \\
Type width & $\mathrm{B}$ & $\mathrm{m}$ & 0.512 & 4.1 \\
Design draught & $\mathrm{T}$ & $\mathrm{m}$ & 0.11875 & 0.95 \\
Wet surface area & $\mathrm{S}$ & $\mathrm{m}$ & 1.33 & 85.7 \\
Scale ratio & $\lambda$ & & 8 & \\
\hline
\end{tabular}

The tank model test model of the pool is shown in Figure 1.
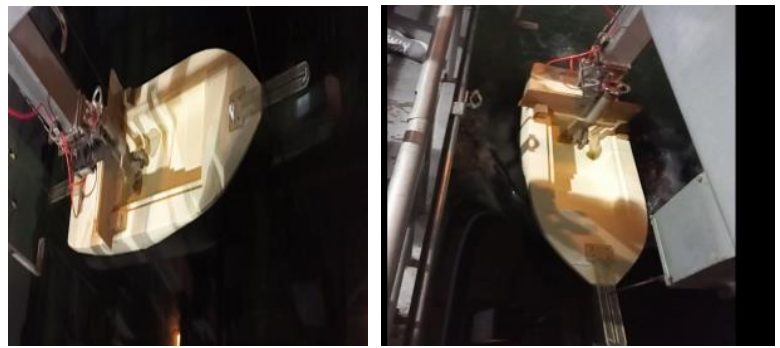

Figure 1 Basin boat model test model

\section{B. 2.2 Model test plan}

Considering the feasibility of the project, the lateral installation position of the keel is as close as possible to the angle line. In this paper, three keel schemes are designed according to the installation position and height of different ribs of the hull. Scheme 1 (light body + attached body \#11-\#19), scheme 2 (light body + attached body \#12-\#20), scheme three (light body + attached body \#12-\#20, based on scheme 2 To the bottom of the ship, $140 \mathrm{~mm}$ down) to analyze its resistance performance. The location of the design keel is shown in Figure 2. 


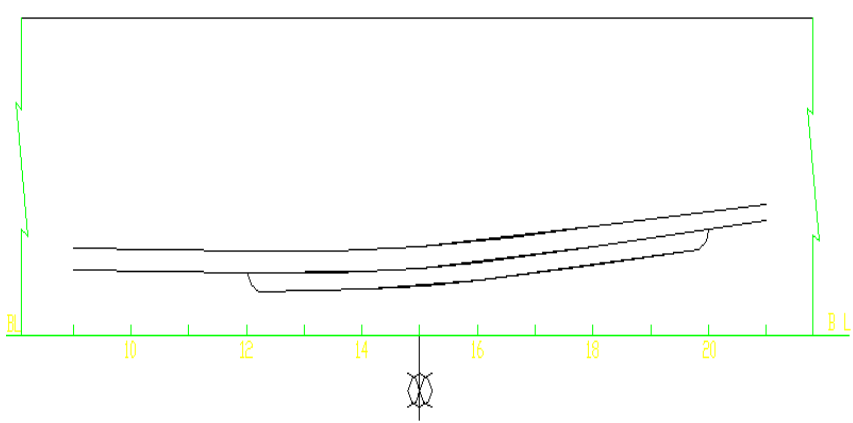

Figure 2 shows the location of the bilge keel

In this test, three different positions of the keel installation scheme were set up, which were towed at a design speed of $2.18 \mathrm{~m} / \mathrm{s}$, and the resistance meter values were recorded. According to the test requirements, the detailed test plan is shown in Table 2.

Table 2 specific plan for ship model resistance test

\begin{tabular}{lll}
\hline $\begin{array}{l}\text { Experimental } \\
\text { state }\end{array}$ & test & model \\
\hline 1 & $\begin{array}{l}\text { Resistance } \\
\text { test }\end{array}$ & Light body \\
& $\begin{array}{l}\text { Resistance } \\
\text { test }\end{array}$ & $\begin{array}{l}\text { Light body + attached body } \\
\text { (\#11-\#19: Option 1) }\end{array}$ \\
& $\begin{array}{l}\text { Resistance } \\
\text { test }\end{array}$ & $\begin{array}{l}\text { Light body + attached body } \\
\text { (\#12-\#20: Option 2) }\end{array}$ \\
& Resistance & $\begin{array}{l}\text { Light body + attached body } \\
\text { (\#12-\#20: Option 3) }\end{array}$ \\
\hline
\end{tabular}

\section{NUMERICAL CALCULATION AND RESULT ANALYSIS}

\section{A. Calculation and verification of bare hull resistance}

According to the main parameters of the pilot vessel and the ship model scale ratio during the pool test, the modeling and boundary conditions (including model size, calculation domain size, water temperature, center of gravity position, etc.) are calculated according to the test environment of the pool model test during the simulation. Combining the characteristics of medium- and high-speed ship navigation, meshing is introduced, and multi-degree-of-freedom coupling calculation is introduced, taking into account the drag effect caused by navigation trim and heave. The specific division of the hull model grid [9] is shown in Figure 3 and Figure 4.

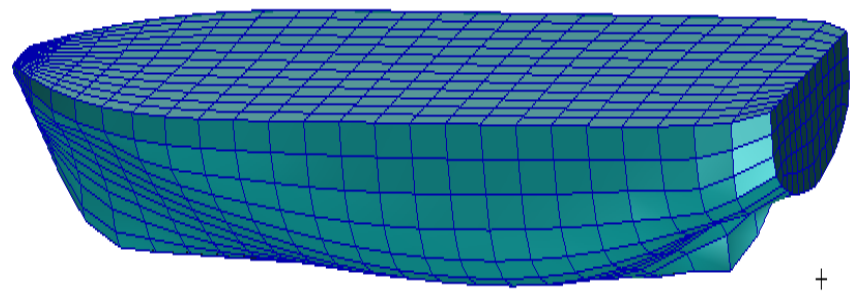

Figure 3 hull model grid specific division

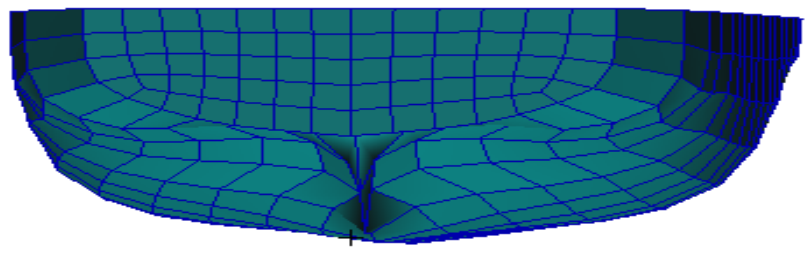

Figure 4 Ship's mesh division
At a scale ratio of 1:8, corresponding to the pool water density of 1000, the ship's wet surface area of 1.339 , the pool water's kinematic viscosity coefficient of 0.014 , and the ship's waterline length of $1.875, \mathrm{C}_{\mathrm{AA}}=0.001 \frac{\mathrm{A}_{\mathrm{T}}}{\mathrm{S}_{\mathrm{S}}}$, the boat model pool resistance is obtained for the ship's mode light. In the test, according to the range of the test speed of the pool, the range of 4 to $23 \mathrm{kn}$ of the actual ship is selected, and 11 speeds are selected in the middle to simulate the total hull resistance. The calculation results and the comparison with the pool test are shown in Table 3.

Table 3 Comparison of calculation results with pool test

\begin{tabular}{llllll}
$\begin{array}{l}\text { Actual } \\
\text { ship } \\
\text { speed }\end{array}$ & $\begin{array}{l}\text { Model } \\
\text { speed }\end{array}$ & Fr & $\begin{array}{l}\text { Simulated } \\
\text { resistance }\end{array}$ & $\begin{array}{l}\text { Test } \\
\text { resista } \\
\text { nce }\end{array}$ & error\% \\
\hline 4.6 & 0.45 & 0.104 & 0.078 & 0.076 & $-2.6 \%$ \\
8.1 & 0.8 & 0.186 & 1.421 & 1.495 & $4.9 \%$ \\
19.86 & 1.95 & 0.45 & 24.36 & 25.73 & $5.3 \%$ \\
20.36 & 2 & 0.466 & 26.96 & 28.75 & $6.2 \%$ \\
20.87 & 2.05 & 0.478 & 28.56 & 31.05 & $8.0 \%$ \\
21.38 & 2.1 & 0.489 & 30.86 & 33.71 & $8.5 \%$ \\
21.89 & 2.15 & 0.499 & 33.72 & 37.22 & $9.4 \%$ \\
22.2 & 2.18 & 0.508 & 36.03 & 39.86 & $9.6 \%$ \\
22.6 & 2.22 & 0.517 & 37.96 & 42.1 & $9.8 \%$ \\
22.91 & 2.25 & 0.524 & 40.45 & 45.02 & $10.2 \%$ \\
23.22 & 2.28 & 0.532 & 42.69 & 47.83 & $10.7 \%$ \\
\hline
\end{tabular}

It can be seen from Table 3 that the results of the numerical simulation and the total resistance of the pool test are basically consistent in the overall trend, and the errors are all within $10 \%$. However, in general, the numerical results are generally lower than the pool test results, and as the speed increases, the error gradually increases. The reason for the analysis may be that the pool is added to the stern during the tank test, and the default wall roughness is used for numerical simulation $^{[10]}$.

\section{B. Analysis of resistance performance of bilge keel}

According to the actual ship's main scale and ship model parameters, the keel is added to the original bare hull at different positions to establish a model for mesh division as shown in Fig. 5.

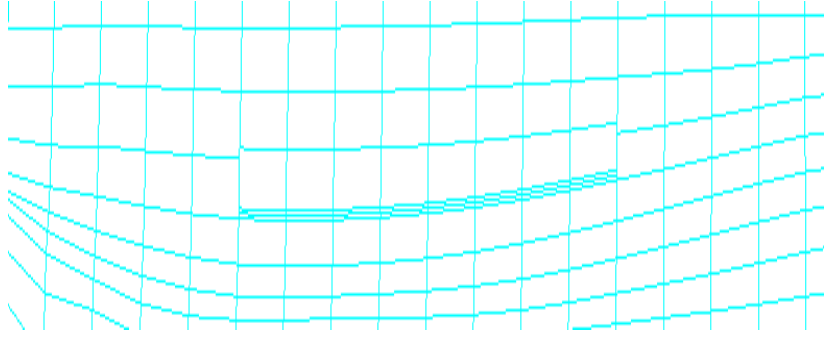

Figure 5 keel meshing

In the original bare hull ship model, the keel was added to carry out the ship model test. The total resistance result and the original bare hull total resistance are shown in Tables 4, 5 and 6. 
Table 4 Calculation results of resistance test of ship model in the case of light body with body (\#11-\#19: Option 1)

\begin{tabular}{|c|c|c|c|c|c|c|c|c|}
\hline $\begin{array}{l}\text { Serial } \\
\text { number }\end{array}$ & 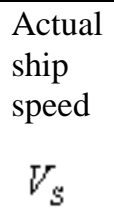 & 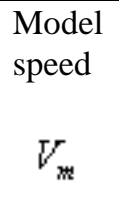 & $\mathrm{Fr}$ & $\begin{array}{l}\text { Bare hull } \\
\text { resistance } \\
\text { / N }\end{array}$ & $\begin{array}{l}\text { Belt keel } \\
\text { resistance / } \\
\mathrm{N}\end{array}$ & $\begin{array}{l}\text { Resistance } \\
\text { increase / } \\
\mathrm{N}\end{array}$ & $\begin{array}{l}\text { Resistance } \\
\text { increase } \\
\text { percentage } \\
\%\end{array}$ & $\begin{array}{l}\mathrm{PE} \\
(\mathrm{KW})\end{array}$ \\
\hline 1 & 4.60 & 0.45 & 0.104 & 0.076 & 0.085 & 0.009 & 11.84 & 0.223 \\
\hline 2 & 8.10 & 0.80 & 0.186 & 1.495 & 1.65 & 0.155 & 10.37 & 4.748 \\
\hline 3 & 19.86 & 1.95 & 0.450 & 25.73 & 28.22 & 2.49 & 9.68 & 97.490 \\
\hline 4 & 20.36 & 2.00 & 0.466 & 28.75 & 31.18 & 2.43 & 8.45 & 112.94 \\
\hline 5 & 20.87 & 2.05 & 0.478 & 31.05 & 33.87 & 2.82 & 9.08 & 128.46 \\
\hline 6 & 21.38 & 2.10 & 0.489 & 33.71 & 36.92 & 3.21 & 9.52 & 140.47 \\
\hline 7 & 21.89 & 2.15 & 0.499 & 37.22 & 40.94 & 3.72 & 9.99 & 154.33 \\
\hline 8 & 22.20 & 2.18 & 0.508 & 39.86 & 43.99 & 4.13 & 10.36 & 167.85 \\
\hline 9 & 22.60 & 2.22 & 0.517 & 42.1 & 46.56 & 4.46 & 10.59 & 180.26 \\
\hline 10 & 22.91 & 2.25 & 0.524 & 45.02 & 49.53 & 4.51 & 10.02 & 194.52 \\
\hline 11 & 23.22 & 2.28 & 0.532 & 47.83 & 52.92 & 5.09 & 10.64 & 210.30 \\
\hline
\end{tabular}

Table 5 Calculation results of resistance test of ship model in the case of light body with body (\#12-\#20: plan 2)

\begin{tabular}{|c|c|c|c|c|c|c|c|c|}
\hline $\begin{array}{l}\text { Serial } \\
\text { number }\end{array}$ & $\begin{array}{l}\text { Actual } \\
\text { ship } \\
\text { speed } \\
V_{S}\end{array}$ & $\begin{array}{c}\text { Model } \\
\text { speed } \\
V_{m}\end{array}$ & $\mathrm{Fr}$ & $\begin{array}{l}\text { Bare hull } \\
\text { resistance / } \\
\mathrm{N}\end{array}$ & $\begin{array}{l}\text { Belt keel } \\
\text { resistance } \\
\text { / N }\end{array}$ & $\begin{array}{l}\text { Resistanc } \\
\text { e increase } \\
\text { / N }\end{array}$ & $\begin{array}{l}\text { Resistance } \\
\text { increase } \\
\text { percentage } \\
\%\end{array}$ & $\begin{array}{l}\mathrm{PE} \\
(\mathrm{KW})\end{array}$ \\
\hline 1 & 4.60 & 0.45 & 0.104 & 0.076 & 0.085 & 0.009 & 11.84 & 0.22 \\
\hline 2 & 8.10 & 0.8 & 0.186 & 1.495 & 1.661 & 0.166 & 11.10 & 4.80 \\
\hline 3 & 19.86 & 1.95 & 0.45 & 25.73 & 28.52 & 2.79 & 10.84 & 99.81 \\
\hline 4 & 20.36 & 2.00 & 0.466 & 28.75 & 31.93 & 3.18 & 11.06 & 115.25 \\
\hline 5 & 20.87 & 2.05 & 0.478 & 31.05 & 34.59 & 3.54 & 11.40 & 130.43 \\
\hline 6 & 21.38 & 2.1 & 0.489 & 33.71 & 37.24 & 3.53 & 10.47 & 143.46 \\
\hline 7 & 21.89 & 2.15 & 0.499 & 37.22 & 40.83 & 3.61 & 9.70 & 158.24 \\
\hline 8 & 22.2 & 2.18 & 0.508 & 39.86 & 43.74 & 3.88 & 9.73 & 171.34 \\
\hline 9 & 22.6 & 2.22 & 0.517 & 42.1 & 46.25 & 4.15 & 9.86 & 184.02 \\
\hline 10 & 22.91 & 2.25 & 0.524 & 45.02 & 48.85 & 3.83 & 8.51 & 198.59 \\
\hline 11 & 23.22 & 2.28 & 0.532 & 47.83 & 51.97 & 4.14 & 8.66 & 214.38 \\
\hline
\end{tabular}

Table 6 Calculation results of resistance test for ship model in the case of light body with body (\#12-\#20: option 3)

\begin{tabular}{|c|c|c|c|c|c|c|c|c|}
\hline $\begin{array}{l}\text { Serial } \\
\text { number }\end{array}$ & $\begin{array}{l}\text { Actual } \\
\text { ship } \\
\text { speed }\end{array}$ & 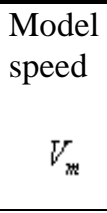 & $\mathrm{Fr}$ & $\begin{array}{l}\text { Bare hull } \\
\text { resistance } \\
\text { / N }\end{array}$ & $\begin{array}{l}\text { Belt keel } \\
\text { resistance / } \\
\mathrm{N}\end{array}$ & $\begin{array}{l}\text { Resistance } \\
\text { increase / } \\
\mathrm{N}\end{array}$ & $\begin{array}{l}\text { Resistance } \\
\text { increase } \\
\text { percentage } \\
\%\end{array}$ & $\begin{array}{l}\mathrm{PE} \\
(\mathrm{KW})\end{array}$ \\
\hline 1 & 4.6 & 0.45 & 0.104 & 0.076 & 0.083 & 0.007 & 9.21 & 0.214 \\
\hline 2 & 8.1 & 0.8 & 0.186 & 1.495 & 1.64 & 0.145 & 9.70 & 4.25 \\
\hline 3 & 19.86 & 1.95 & 0.45 & 25.73 & 28.01 & 2.28 & 8.86 & 89.706 \\
\hline 4 & 20.36 & 2 & 0.466 & 28.75 & 31.27 & 2.52 & 8.77 & 110.69 \\
\hline 5 & 20.87 & 2.05 & 0.478 & 31.05 & 33.29 & 2.24 & 7.21 & 125.16 \\
\hline 6 & 21.38 & 2.1 & 0.489 & 33.71 & 36.37 & 2.66 & 7.89 & 136.44 \\
\hline 7 & 21.89 & 2.15 & 0.499 & 37.22 & 39.9 & 2.68 & 7.20 & 150.07 \\
\hline 8 & 22.2 & 2.18 & 0.508 & 39.86 & 42.29 & 2.43 & 6.10 & 163.28 \\
\hline 9 & 22.6 & 2.22 & 0.517 & 42.1 & 44.29 & 2.19 & 5.20 & 176.4 \\
\hline 10 & 22.91 & 2.25 & 0.524 & 45.02 & 47.15 & 2.13 & 4.73 & 190.28 \\
\hline 11 & 23.22 & 2.28 & 0.532 & 47.83 & 50.35 & 2.52 & 5.27 & 204.17 \\
\hline
\end{tabular}

It can be seen from Tables 4,5 and 6 that the total resistance of the whole ship after the increase of the bilge keel will increase accordingly, and the increase of the value of the scheme 3 is about $6 \%$ near the design speed. In addition, as the speed increases, the resistance increase due to the keel keel will gradually increase, but the proportion of the resistance increase in the total resistance gradually decreases
${ }^{[11]}$. Three different keel installation location schemes, scheme 3 has the least resistance and is relatively stable, which is $3 \%$ and $4 \%$ less than scheme 1 and scheme 2 respectively. Therefore, the ship scheme selects the keel installation position of scheme 3 . According to the preliminary analysis, in the case of reasonable design of the keel keel, it will not have a greater impact on the pressure 
distribution and wave propagation on the hull surface. The effect on the total resistance is mainly to increase the frictional resistance of the hull.

The ship model resistance and the actual ship effective power curve under different conditions are shown in Figures 6 and 7.

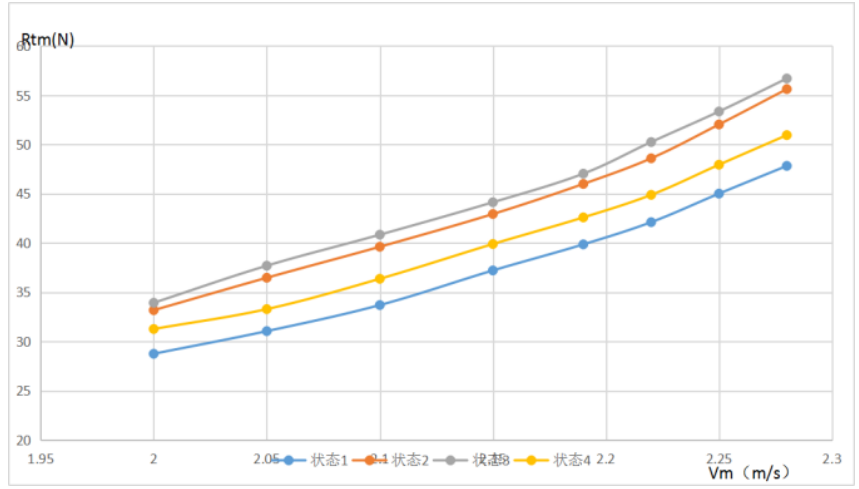

Figure 6 Ship model resistance curve

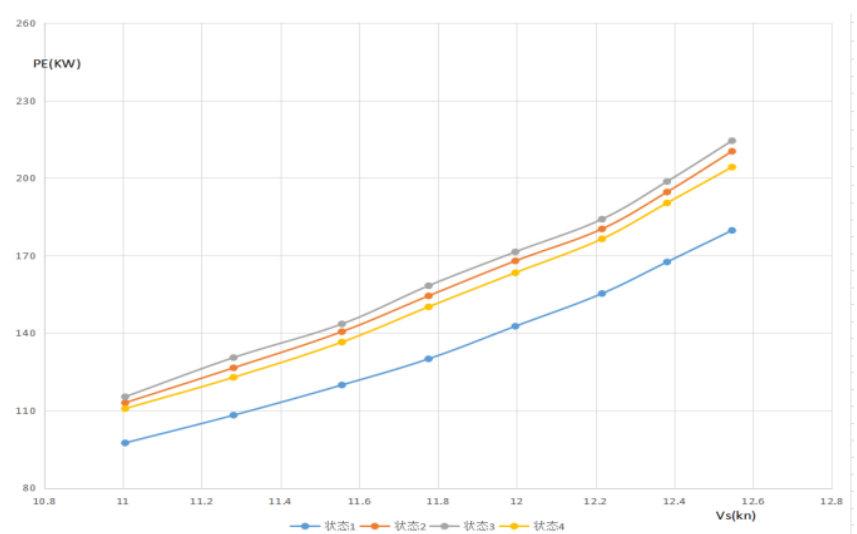

Figure 7 actual ship effective powcurve

The optimal installation position of the keel obtained by the above test analysis is shown in the third scheme of Fig. 8.

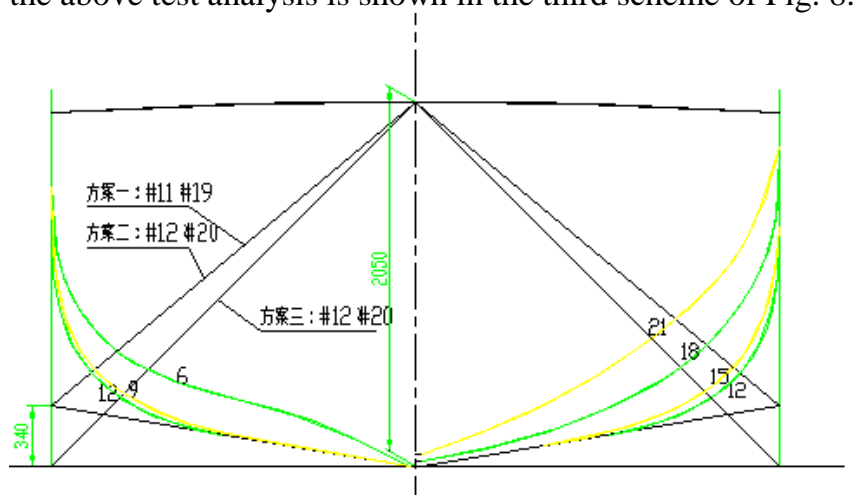

Figure 8 keel installation location

\section{CONCLUSION}

In this paper, through the ship model pool test and numerical calculation, the resistance performance of the ship model and the actual ship with the keel are compared and analyzed. According to the test and calculation data, the results are as follows:

1) By comparing the results of numerical simulation with the total resistance of the pool test, the overall trend is basically the same, the error is within $10 \%$, but the result of the pool test is slightly larger than the numerical calculation due to the increase of the torrent in the bow during the pool test. Results: Compared with the original flawless keel scheme, the resistance of the preferred scheme is slightly increased. Corresponding to the design speed of the actual ship, the hydrostatic resistance of the preferred scheme is increased compared with the original flawless keel scheme, and the resistance increase value is less than $6 \% \mathrm{Rtm}$.

2) Through the comparative analysis of three different keel installation position schemes, the scheme 3 has the least resistance, which is $3 \%$ and $4 \%$ less than scheme 1 and scheme 2 respectively. Therefore, the ship plan selects the keel keel installation position of scheme 3 .

3) The analysis results of the typical bilge keel on the hull resistance performance are representative, and can be used as a reference for the design of such medium and high speed speedboat keel. However, the influence of parameters such as the shape and angle of the same keel on the resistance has not been analyzed in depth, and further research is needed in the follow-up work. The research on the layout method of the keel keel expands the means for the ship industry to solve related problems and has certain academic significance.

\section{REFERENCES}

[1] Yu Xiangsan, Chen Zeliang, Lou Liangen et al. Ship performance experiment technology [M]. Shanghai: Shanghai Jiaotong University Press, 1991.

[2] Yang Hui, Song Jinlong. Introduction and development trend of ship anti-rolling method [J]. Jiangsu Ship, 2007 (5): 55-58.

[3] Jin Hongzhang, Zhao Weiping. Research on comprehensive anti-rolling system for large ships [J]. China Shipbuilding, 2005 (2): 88-92.

[4] Ganshui comes. keel structure design and installation research [J]. Ship Engineering, 2012 (2): 27-55.

[5] Fu Jiangyan, Chen Yu, Ge Huixiao. The effect of adding 舭 keel on the hydrostatic resistance and roll motion of a thousand-ton deep V ship [J]. Chinese Ship Research, 2015, 10( 5) : 22-26.

[6] Fang advanced, Zhu Renchuan, Xu Wenshan and so on. Analysis of resistance performance of a medium-high speed fishery ship [J]. Ship and Sea Engineering, 2016, 45 (6): 11-14.

[7] Ansys inc. ANSYS FLUENT User's Guide(12.0)[Z]. 2010.

[8] Sun Changlong. Determination of main parameters of ship model towing pool $[\mathrm{J}]$. Journal of Wuhan Institute of Water Transport Engineering, 1981 (2): 102-107.

[9] Qiu Yunming, Deng Rui. Research on mesh division method in ship resistance calculation [J]. Ship Engineering, 2013, 35( 1) : 13-15.

[10] Yang Jianmin, Xiao Longfei, Sheng Zhenbang. Marine engineering hydrodynamic experimental study [M]. Shanghai: Shanghai Jiaotong University Press, 2008.

[11] Xu Hui, Chen Li, Qin Jiangtao. Study on the influence of different combinations of fin stabilizer and keel keel on ship rapidity [J]. Transportation Science and Engineering Edition, 2013, 37(4): 43-63. 